\title{
Predictors of exposure to secondhand tobacco smoke among non-smoking in-school adolescents in Ibadan, Nigeria
}

\author{
Omotayo F. Fagbule ${ }^{1}$, Mary E. Osuh ${ }^{1,2}$
}

\section{AFFILIATION}

1 Department of Periodontology and Community Dentistry, University College Hospital, Ibadan, Nigeria

2 Department of Periodontology and Community Dentistry, College of Medicine, University of Ibadan, Ibadan, Nigeria

\section{CORRESPONDENCE TO}

Omotayo F. Fagbule. Department of Periodontology and Community Dentistry, University College Hospital, Queen Elizabeth Road, Ibadan, Nigeria. E-mail: ffagbule@gmail.com ORCID ID: https://orcid.org/00000002-1351-9659

Popul. Med. 2020;2(July):22

\section{KEYWORDS}

secondhand smoke, tobacco, environmental tobacco smoke, adolescent, Nigeria, passive smoking

Received: 26 March 2020, Revised: 18 June 2020, Accepted: 13 July 2020

https://doi.org/10.18332/popmed/125362

\begin{abstract}
INTRODUCTION Exposure to secondhand smoke (SHS) has proven to be a public health problem. The problem is even worse among vulnerable groups like non-smoking children and adolescents. There is limited information on SHS exposure among Nigerian adolescents; thus, this study aims to describe the predictors of exposure to SHS among nonsmoking, in-school adolescents in Ibadan, Nigeria.

METHODS A cross-sectional study was conducted among randomly-selected non-smoking in-school adolescents $(n=825)$, from 18 secondary schools in Ibadan, Nigeria. Using the GYTS questionnaires, respondents' exposure to SHS was determined in relation to location: inside home, outside home, both inside and outside home, and either inside or outside home. Data were analyzed using descriptive statistics, bivariate analysis, and logistic regression model $(\alpha=0.05)$.

RESULTS Participants' mean age was $14(\mathrm{SD}=1.72)$ years, and they belonged to high, middle and low social class in the following respective proportions: $49.5 \%, 30.3 \%$ and $20.1 \%$.
\end{abstract}

The prevalence of exposure to SHS were: inside home (6.1\%), outside home (31.5\%), both inside and outside home (5.1\%), and either inside or outside home (32.5\%). The majority $(56.2 \%)$ perceived that most of their peers smoke. Having a smoking friend (AOR=2.62; 95\% CI: 1.58-4.37) and smoking family $(A O R=2.08 ; 95 \% \mathrm{CI}: 1.32-3.28)$, going on tobacco errands (AOR=3.32; 95\% CI: 1.79-6.17), believing their peers smoke (AOR=1.48; 95\% CI: 1.07-2.05) and belonging to a low social class (AOR=1.66; 95\% CI: 1.05-2.62) were identified as predictors of exposure to SHS either inside or outside home.

CONCLUSIONS One in every three adolescents was exposed to tobacco smoke either inside or outside home, and exposure to SHS outside home was higher than inside home. The high prevalence of secondhand tobacco smoking among in-school adolescents in Ibadan suggests that the smoke-free policy in Nigeria needs to be strengthened. Besides a comprehensive smoke-free environment, other tobacco-control interventions should extend to non-smoking adolescents, especially those having the predictors of SHS exposure found in this study.

\section{INTRODUCTION}

Secondhand smoke (SHS) refers to either smoke from burning tobacco products (sidestream smoke) or that exhaled by smokers (exhaled mainstream smoke) ${ }^{1,2}$. Exposure to secondhand tobacco smoke (SHS) is an important public health problem worldwide ${ }^{3-5}$, with one-third of adults reported to be regularly exposed to it worldwide ${ }^{4}$. This problem is serious among children and adolescent nonsmokers $^{5,6}$. Worldwide, it was estimated about a decade ago that SHS exposure kills over 0.6 million people each year ${ }^{4,7}$.
Moreover, with the increased prevalence in tobacco smoking reported, especially in Low and Middle-Income Countries (LMICs) such as Nigeria, the number of people that die yearly from exposure to SHS may have increased substantially.

Exposure to SHS has been found to have several illhealth effects on those exposed, especially the children and adolescents. These include mental health disorders, atherosclerosis, kidney problems, upper and lower acute respiratory tract infections, acute and chronic ear infections, exacerbation of asthma, and adverse growth outcomes in 
children $^{8-13}$. Other reported health hazards are: bladder cancer, increased lead in the bloodstream, cognitive impairment and poor academic performance ${ }^{14-16}$. Reported oral effects include pigmentation of the gums, periodontitis, caries, tooth loss and orofacial cleft ${ }^{17-21}$. Exposure to SHS is also significantly associated with the uptake of tobacco smoking habit during the adolescent stage of growth ${ }^{6,22,23}$, a development which is posing a public health problem.

Though the law restricting smoking in public spaces has led to significantly reduced exposure to $\mathrm{SHS}^{4}$, the overall prevalence of exposure to SHS is still high even in countries that have banned smoking in public places ${ }^{5}$. Factors reported to be associated with a high risk of exposure to SHS among adolescents are: having a smoking friend or smoking family member, inadequate knowledge about the harmful effects of tobacco smoke, poor attitude towards tobacco smoking, and ban of tobacco use in public places s, $22,24,25^{\text {. }}$

There is a paucity of research on the burden of exposure to SHS among adolescents in Nigeria. The last survey among school-going adolescents using GYTS was conducted in 2008, and a high prevalence of exposure to SHS among schoolgoing adolescents was reported, though varied across the five cities where the survey was conducted. The prevalence of both home and public (outside home) exposure to SHS was lowest in Ibadan at $14.5 \%$ and $25 \%$, respectively, while home exposure was highest in Calabar (31.3\%) and public exposure was highest in Kano $(55.8 \%)^{26}$. However, a recent study $^{27}$ on outdoor (motor-parks, roadsides and street corners) tobacco smoking conducted in Ibadan city revealed a prevalence of $63.8 \%$. With such values in the prevalence of tobacco smoking in open spaces, it becomes important to document the SHS exposure level in Ibadan, especially among non-smoking adolescents. Such information has the potential to highlight specific areas for intervention in both oral and general health promotion and disease prevention among the adolescents and youths.

A proper understanding of the severity of the exposure to SHS among adolescents and its associated factors will facilitate the development of an effective intervention to curtail it. Thus, this study aimed at estimating the current prevalence and determinants of exposure to SHS both at home and outside home, among non-tobacco smoking adolescents who were enrolled in schools in the Ibadan metropolis, Nigeria.

\section{METHODS}

\section{Study design}

A descriptive cross-sectional study was conducted in Ibadan metropolis, Oyo State, Nigeria. The metropolitan part of the city of Ibadan has five Local Government Areas (LGAs). The typical secondary schools have six class levels (Junior and Senior secondary schools, 1-3).

\section{Study population and selection of study participants}

The study was carried out among adolescents who were enrolled in both public and private secondary schools, irrespective of their smoking status. Only adolescents between the ages of 10 and 19 years and who had completed at least one year in the school were included in the study. Consequently, the students in the Junior Secondary School 1 (JSS1) classes were excluded.

Multistage sampling technique was used in selecting the study participants. Three LGAs out of the Five LGAs were randomly selected from the study area. A list of all the secondary schools (public and private) in each of the selected LGAs was obtained from the Ministry of Education, Oyo State. From the list, six secondary schools (three public and three private) were selected in each of the three LGAs using simple random sampling method, making a total of 18 schools. Finally, from each of the selected schools, 10 students were selected per class: Junior Secondary School 2 to Senior Secondary School 3 (JSS2 to SSS3) using stratified sampling method.

\section{Data collection procedure}

A self-administered semi-structured questionnaire was used for data collection. The questionnaire was adapted from the standardized questionnaire for Global Youth Tobacco Survey (GYTS) ${ }^{28}$ and literature ${ }^{29,30}$. Of the total of 900 selected study participants, 39 declined participation in the research. These were mainly the SSS 3 students, who attributed their nonparticipation to the fast-approaching Senior Secondary School Leaving Certificate Examinations. Thus, the total number of respondents was 861. Ethical approval (UI/ EC/18/0243) was obtained from the University of Ibadan/ University College Hospital Ethics Review Board before the commencement of the study. Permission was obtained from both the Ministry of Education, Oyo State and the school principals of the selected secondary schools. Consent and assent were obtained from the parents/guardians and the students, respectively, before the conduct of the study. The respondents were assured of the confidentiality and anonymity of the information they provided.

\section{Study measures}

The outcome variable is exposure to SHS. This outcome was further categorized based on the location where the exposure occurred. These included exposure: inside home, outside home, both inside and outside home, and either inside or outside home. Exposure to SHS inside and/or outside the home was determined based on the answer to the questions: 'During the past 7 days, on how many days has anyone smoked inside your home, in your presence?' and 'During the past 7 days, on how many days has anyone smoked in your

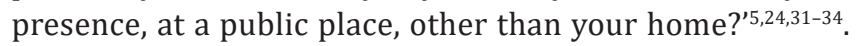
A respondent's status to SHS exposure whether inside and/ or outside home was determined to be negative only if a ' 0 days' option was selected; otherwise, he/she was classified as exposed. As with similar studies, the responses of the participants were used to determine respondents who were exposed 'both inside home and outside home' by combining only those that responded positively to both 'SHS exposure 
at home' and 'SHS exposure outside home ${ }^{24,32-34}$. Exposure to 'either inside or outside home' was ascertained from participants that answered positively to either 'SHS exposure at home' or 'SHS exposure outside home' ${ }^{35}$.

Smoking status of the participants was determined using the questions: 'Have you ever smoked cigarette, even if it is one or two puffs?' and 'During the past 30 days, on how many days did you smoke cigarettes?'. Those who responded negatively to the two questions were classified as 'never smokers' and 'non-current smokers', respectively; they constituted the study population for this study (never/non-current smokers).

The social class of the participants was determined based on the classification by Oyedeji et al. ${ }^{36}$. Different scores were allocated to the educational level and occupation of the respondents' parents/guardians, and the average score per participant was calculated. Following this, the respondents were further categorized into low, middle or high social class based on their scores ${ }^{36}$. Perception about the adverse effect of tobacco smoking and the exposure to SHS was assessed by the question: 'Do you think the smoke from other people's tobacco smoking is harmful to you?' and 'Do you think smoking tobacco is harmful to your health?'. The options were: 'Definitely not', 'Probably not', 'Probably yes', and 'Definitely yes'. The first two options were later merged into 'no' and the last two options combined as 'yes'. Another independent variable was the adolescents' participation in tobacco errands, which was assessed by asking: 'Do the elder ones in your household and community send you on errands to buy tobacco/cigarettes?' with 'yes' and 'no' as the options.

\section{Statistical analysis}

The data were analyzed using Statistical Package for Social Sciences (SPSS) version 25. Only the data of respondents with the characteristic of interest (non-current smokers) were analyzed. Descriptive analysis of the continuous variables are presented as means with standard deviation, while categorical variables, such as the sociodemographic and the outcome variables, are presented as proportions. Associations between the outcome variables (exposure to SHS at different locations) and the independent variables such as age, gender, smoking status of parents and of close friends, attitude towards smoking and knowledge about harmful effects of smoking and exposure to tobacco smoke were based on chisquared test. Multiple logistic regression model was used to estimate the relationship between the independent variables and exposure to SHS. The adjusted odds ratios (AOR) and $95 \%$ confidence intervals $(95 \% \mathrm{CI})$ are reported. All statistical inferences are based on 5\% significance level.

\section{RESULTS}

The total number of respondents who were either never smokers or non-smokers was 825, with a mean age of 14 ( $\mathrm{SD}=1.72)$ years, of which $421(51.0 \%)$ were males (Table 1). About half $(49.5 \%)$ of the respondents belonged to a high social class, and $464(56.2 \%)$ were of the opinion that
Table 1. Sociodemographic characteristics and prevalence estimates of predictors of exposure to secondhand tobacco smoke (SHS) among non-smoking, in-school adolescents in Ibadan, Nigeria, 2018 ( $\mathrm{N}=825)$

\begin{tabular}{|c|c|c|}
\hline Characteristics & n & $\%$ \\
\hline \multicolumn{3}{|l|}{ Age (years) } \\
\hline $10-14$ & 462 & 56.0 \\
\hline $15-19$ & 363 & 44.0 \\
\hline \multicolumn{3}{|l|}{ Gender } \\
\hline Male & 421 & 51.0 \\
\hline Female & 404 & 49.0 \\
\hline \multicolumn{3}{|l|}{ School type } \\
\hline Public & 411 & 49.8 \\
\hline Private & 414 & 50.2 \\
\hline \multicolumn{3}{|l|}{ Class } \\
\hline Junior & 359 & 43.5 \\
\hline Senior & 466 & 56.5 \\
\hline \multicolumn{3}{|l|}{ Parents living together } \\
\hline No & 71 & 8.6 \\
\hline Yes & 754 & 91.4 \\
\hline \multicolumn{3}{|l|}{ House type } \\
\hline One room apartment & 55 & 6.7 \\
\hline Two rooms & 134 & 16.2 \\
\hline Three rooms or more & 636 & 77.1 \\
\hline \multicolumn{3}{|l|}{ Social class } \\
\hline High & 408 & 49.5 \\
\hline Middle & 250 & 30.3 \\
\hline Low & 166 & 20.1 \\
\hline \multicolumn{3}{|l|}{ Most of my peers smoke } \\
\hline I believe this & 464 & 56.2 \\
\hline I don't believe this/not sure & 361 & 43.8 \\
\hline \multicolumn{3}{|l|}{ Smoking friend } \\
\hline No & 741 & 89.8 \\
\hline Yes & 84 & 10.2 \\
\hline \multicolumn{3}{|l|}{ Smoking family member } \\
\hline No & 724 & 87.8 \\
\hline Yes & 101 & 12.2 \\
\hline \multicolumn{3}{|l|}{ Sent on tobacco errands } \\
\hline Yes & 56 & 6.8 \\
\hline No & 769 & 93.2 \\
\hline \multicolumn{3}{|l|}{ SHS is harmful } \\
\hline No & 180 & 21.8 \\
\hline Yes & 645 & 78.2 \\
\hline \multicolumn{3}{|l|}{ Tobacco smoking is harmful } \\
\hline No & 102 & 12.4 \\
\hline Yes & 723 & 87.6 \\
\hline \multicolumn{3}{|c|}{$\begin{array}{l}\text { Can one purchase tobacco near my } \\
\text { school }\end{array}$} \\
\hline No/not sure & 773 & 93.7 \\
\hline Yes & 52 & 6.3 \\
\hline
\end{tabular}


the majority of their peers smoked tobacco (Table 1). About $10.2 \%$ and $12.2 \%$ of the adolescents had close friends and family members who smoke, respectively, while 56 (6.8\%) of the respondents ran errands to buy tobacco products for adults (Table 1).

\section{Exposure to SHS}

The prevalence of exposure to SHS 'inside home', 'outside home', 'both inside and outside home' and 'either inside or outside home' were $6.1 \%, 31.5 \%, 5.1 \%$, and $32.5 \%$, respectively (Table 2). Even though only $6.1 \%$ were exposed at home, most $(84.0 \%)$ were also exposed to SHS outside

Table 2. Percentage distribution of exposure to secondhand tobacco smoke (SHS) among non-smoking, school-going adolescents in Ibadan, 2018 ( $\mathrm{N}=825)$

\begin{tabular}{|c|c|c|}
\hline Exposure to SHS & n & $\%$ \\
\hline \multicolumn{3}{|l|}{ Inside home } \\
\hline No & 775 & 93.9 \\
\hline Yes & 50 & 6.1 \\
\hline \multicolumn{3}{|l|}{ Outside home } \\
\hline No & 565 & 68.5 \\
\hline Yes & 260 & 31.5 \\
\hline \multicolumn{3}{|c|}{ Both inside and outside home } \\
\hline No & 783 & 94.9 \\
\hline Yes & 42 & 5.1 \\
\hline \multicolumn{3}{|c|}{ Either inside or outside home } \\
\hline No & 557 & 67.5 \\
\hline Yes & 268 & 32.5 \\
\hline
\end{tabular}

their homes. On bivariate analysis, factors such as the school type, house type, social class, having a smoking friend and smoking family, and going on errands to buy tobacco products, were significantly associated $(\mathrm{p}<0.05)$ with all the four forms of exposure to SHS (Table 3). However, following the logistic regression analysis, the following factors were predictors of exposure to SHS: having a family member who smokes (AOR=4.56; 95\% CI: 2.36-8.80) and going on errands to buy tobacco products (AOR=3.11; 95\% CI: $1.40-6.91$ ) were found to be independently associated with exposure to SHS at home. Similar factors were also associated with the exposure to SHS, both inside and outside home (Table 4). As for exposure to SHS outside home, those who had smoking family members (AOR $=1.75$; 95\% CI: 1.10-2.76) or friends (AOR=2.62; 95\% CI: 1.58-4.35), who were sent on errands to buy tobacco products (AOR=3.59; $95 \% \mathrm{CI}$ : 1.93-6.65), and respondents who believed most of their peers smoke (AOR=1.48; 95\% CI: 1.07-2.05) were significantly associated with increased odds of SHS exposure outside home (Table 4). The predictors of exposure to SHS inside or outside home included all the factors that were significantly associated with exposure outside home, as well as belonging to a low social class (OR=1.66; 95\% CI: 1.05-2.62; $\mathrm{p}=0.03$ ) (Table 4).

\section{Perception of harm from passive and active tobacco smoking}

One in every five of the non-smoking adolescents did not believe that exposure to SHS is harmful, and $12.4 \%$ disagreed that tobacco smoking is harmful to their health (Table 1). Overall, the study shows that non-smoking adolescents who had a better knowledge of the harm from exposure to tobacco smoke and tobacco smoking itself, were more exposed to SHS across all the locations.

Table 3. Factors associated with exposure to secondhand tobacco smoke (SHS) among in-school adolescents in Ibadan, Nigeria, 2018

\begin{tabular}{|c|c|c|c|c|c|c|c|c|}
\hline \multirow[t]{3}{*}{ Characteristics } & \multicolumn{8}{|c|}{ Exposure to SHS } \\
\hline & \multicolumn{2}{|c|}{$\begin{array}{l}\text { Inside home } \\
50(6.1 \%)\end{array}$} & \multicolumn{2}{|c|}{$\begin{array}{l}\text { Outside home } \\
260(31.5 \%)\end{array}$} & \multicolumn{2}{|c|}{$\begin{array}{c}\text { Both inside and } \\
\text { outside home } \\
42(5.1 \%)\end{array}$} & \multicolumn{2}{|c|}{$\begin{array}{c}\text { Either inside or } \\
\text { outside home } \\
268(32.5 \%) \\
\end{array}$} \\
\hline & n (\%) & $\mathbf{p}$ & n (\%) & $\mathbf{p}$ & n (\%) & $\mathbf{p}$ & n (\%) & $\mathbf{p}$ \\
\hline Age (years) & & 0.557 & & $0.005^{\mathrm{a}}$ & & 0.421 & & $0.007^{\mathrm{a}}$ \\
\hline $10-14$ & $26(5.6)$ & & $127(27.5)$ & & $21(4.5)$ & & $132(28.6)$ & \\
\hline $15-19$ & $24(6.6)$ & & $133(36.6)$ & & $21(5.8)$ & & $136(37.5)$ & \\
\hline School type & & $0.003^{\mathrm{a}}$ & & $0.004^{\mathrm{a}}$ & & $0.004^{\mathrm{a}}$ & & $0.002^{\mathrm{a}}$ \\
\hline Public & $35(8.5)$ & & $149(36.3)$ & & $30(7.3)$ & & $154(37.5)$ & \\
\hline Private & $15(3.6)$ & & $111(26.8)$ & & $12(2.9)$ & & $114(27.5)$ & \\
\hline \multirow[t]{2}{*}{ Parents living together } & & $0.015^{\mathrm{a}}$ & & 0.133 & & 0.056 & & 0.066 \\
\hline & & $0.031^{\mathrm{b}, \mathrm{a}}$ & & & & $0.081^{\mathrm{b}}$ & & \\
\hline No & $9(12.7)$ & & $28(39.4)$ & & $7(9.9)$ & & $30(42.3)$ & \\
\hline Yes & $41(5.4)$ & & $232(30.8)$ & & $35(4.6)$ & & $238(31.6)$ & \\
\hline
\end{tabular}


Table 3. Continued

\begin{tabular}{|c|c|c|c|c|c|c|c|c|}
\hline \multirow[t]{3}{*}{ Characteristics } & \multicolumn{8}{|c|}{ Exposure to SHS } \\
\hline & \multicolumn{2}{|c|}{$\begin{array}{l}\text { Inside home } \\
50(6.1 \%)\end{array}$} & \multicolumn{2}{|c|}{$\begin{array}{l}\text { Outside home } \\
260(31.5 \%)\end{array}$} & \multicolumn{2}{|c|}{$\begin{array}{l}\text { Both inside and } \\
\text { outside home } \\
42(5.1 \%)\end{array}$} & \multicolumn{2}{|c|}{$\begin{array}{c}\text { Either inside or } \\
\text { outside home } \\
268(32.5 \%)\end{array}$} \\
\hline & n (\%) & $\mathbf{p}$ & n (\%) & $\mathbf{p}$ & n (\%) & $\mathbf{p}$ & n (\%) & $\mathbf{p}$ \\
\hline House type & & $0.001^{\mathrm{a}}$ & & $0.018^{\mathrm{a}}$ & & $<0.001^{\mathrm{a}}$ & & $0.031^{\mathrm{a}}$ \\
\hline One room apartment & 7 (12.7) & & $25(45.5)$ & & 7 (12.7) & & $25(45.5)$ & \\
\hline Two rooms & $15(11.2)$ & & $49(36.6)$ & & $14(10.4)$ & & $50(37.3)$ & \\
\hline Three rooms or more & $28(4.4)$ & & $186(29.2)$ & & $21(3.3)$ & & $193(30.3)$ & \\
\hline Social class & & $0.004^{\mathrm{a}}$ & & $0.004^{\mathrm{a}}$ & & $0.038^{\mathrm{a}}$ & & $0.001^{\mathrm{a}}$ \\
\hline Low & $18(10.8)$ & & $65(39.2)$ & & $13(7.8)$ & & $70(42.2)$ & \\
\hline Middle & $17(6.8)$ & & $87(34.8)$ & & $16(6.4)$ & & $88(35.2)$ & \\
\hline High & $15(3.7)$ & & $107(26.2)$ & & $13(3.2)$ & & $109(26.7)$ & \\
\hline Most of my peers smoke & & 0.084 & & $<0.001^{\mathrm{a}}$ & & 0.086 & & $<0.001^{\mathrm{a}}$ \\
\hline I believe this & $34(7.3)$ & & $174(37.5)$ & & $29(6.3)$ & & $179(38.6)$ & \\
\hline $\begin{array}{l}\text { I don`t believe this/not } \\
\text { sure }\end{array}$ & $16(4.4)$ & & $86(23.8)$ & & $13(3.6)$ & & $89(24.7)$ & \\
\hline Have a smoking friend & & $0.004^{\mathrm{a}}$ & & $<0.001^{\mathrm{a}}$ & & $0.003^{\mathrm{a}}$ & & $<0.001^{\mathrm{a}}$ \\
\hline No & $39(5.3)$ & & $211(28.5)$ & & $32(4.3)$ & & $218(29.4)$ & \\
\hline Yes & $11(13.1)$ & & $49(58.3)$ & & $10(11.9)$ & & $50(59.5)$ & \\
\hline $\begin{array}{l}\text { Have a smoking family } \\
\text { member }\end{array}$ & & $<0.001^{\mathrm{a}}$ & & $<0.001^{\mathrm{a}}$ & & $<0.001^{\mathrm{a}}$ & & $<0.001^{\mathrm{a}}$ \\
\hline No & $30(4.1)$ & & $211(29.1)$ & & $26(3.6)$ & & 215 (29.7) & \\
\hline Yes & $20(19.8)$ & & $49(48.5)$ & & $16(15.8)$ & & $53(52.5)$ & \\
\hline Send on tobacco errands & & $<0.001^{\mathrm{a}}$ & & $<0.001^{\mathrm{a}}$ & & $<0.001^{\mathrm{a}}$ & & $<0.001^{\mathrm{a}}$ \\
\hline Yes & $12(21.4)$ & & $38(67.9)$ & & $12(21.4)$ & & $38(67.9)$ & \\
\hline No & $38(4.9)$ & & 222 (28.9) & & $30(3.9)$ & & 230 (29.9) & \\
\hline \multirow{2}{*}{$\begin{array}{l}\text { Can one purchase } \\
\text { tobacco near my school }\end{array}$} & & 0.928 & & $0.019^{\mathrm{a}}$ & & 0.818 & & $0.030^{\mathrm{a}}$ \\
\hline & & $1.000^{\mathrm{b}}$ & & & & $0.743^{\mathrm{b}}$ & & \\
\hline No/not sure & $47(6.1)$ & & $236(30.5)$ & & $39(5.0)$ & & 244 (31.6) & \\
\hline Yes & $3(5.8)$ & & $24(46.2)$ & & $3(5.8)$ & & $24(46.2)$ & \\
\hline
\end{tabular}

a Significant. b Fisher's exact test.

Table 4. Predictors of exposure to secondhand tobacco smoke (SHS) among in-school adolescents in Ibadan, Nigeria, 2018

\begin{tabular}{|c|c|c|c|c|}
\hline \multirow[t]{3}{*}{ Variables } & \multicolumn{4}{|c|}{ Exposure to SHS } \\
\hline & Inside home & Outside home & $\begin{array}{l}\text { Both inside and } \\
\text { outside home }\end{array}$ & $\begin{array}{c}\text { Either inside or } \\
\text { outside home }\end{array}$ \\
\hline & AOR (95\% CI) & AOR $(95 \% \mathrm{CI})$ & AOR $(95 \% \mathrm{CI})$ & AOR $(95 \% \mathrm{CI})$ \\
\hline \multicolumn{5}{|c|}{ Have a smoking family } \\
\hline Yes & $4.56(2.36-8.80)$ & $1.75(1.10-2.76)$ & $3.59(1.76-7.33)$ & $2.08(1.32-3.28)$ \\
\hline No (Ref.) & 1.00 & 1.00 & 1.00 & 1.00 \\
\hline
\end{tabular}


Table 4. Continued

\begin{tabular}{|c|c|c|c|c|}
\hline \multirow[t]{3}{*}{ Variables } & \multicolumn{4}{|c|}{ Exposure to SHS } \\
\hline & Inside home & Outside home & $\begin{array}{l}\text { Both inside and } \\
\text { outside home }\end{array}$ & $\begin{array}{l}\text { Either inside or } \\
\text { outside home }\end{array}$ \\
\hline & AOR $(95 \% \mathrm{CI})$ & AOR $(95 \% \mathrm{CI})$ & AOR $(95 \% \mathrm{CI})$ & AOR $(95 \% \mathrm{CI})$ \\
\hline \multicolumn{5}{|l|}{ Sent on tobacco errands } \\
\hline Yes & $3.11(1.40-6.91)$ & $3.59(1.93-6.65)$ & $3.95(1.75-8.90)$ & 3.32 (1.79-6.17) \\
\hline No (Ref.) & 1.00 & 1.00 & 1.00 & 1.00 \\
\hline \multicolumn{5}{|l|}{ Have a smoking friend } \\
\hline Yes & & $2.62(1.58-4.35)$ & & $2.62(1.58-4.37)$ \\
\hline No (Ref.) & & 1.00 & & 1.00 \\
\hline \multicolumn{5}{|l|}{ Most of my peers smoke } \\
\hline I believe this & & $1.48(1.07-2.05)$ & & $1.48(1.07-2.05)$ \\
\hline I don't believe/not sure (Ref.) & & 1.00 & & 1.00 \\
\hline \multicolumn{5}{|l|}{ Social class } \\
\hline Low & & & & $1.66(1.05-2.62)$ \\
\hline Middle & & & & $1.33(0.89-1.97)^{\mathrm{a}}$ \\
\hline High (Ref.) & & & & 1.00 \\
\hline
\end{tabular}

\section{DISCUSSION}

We found that about one in every three participants was exposed to tobacco smoke either inside or outside home, the associated factors were: having a smoking family member or smoking friend, running tobacco errands, believing that most of their peers smoke, and belonging to the lowest social class. The prevalence of exposure to SHS at home (6.1\%) was much lower compared to exposure outside the home $(31.5 \%)$, and this finding is generally in agreement with most other studies conducted in Nigeria ${ }^{26,37}$, West Africa ${ }^{31,34}$, Africa ${ }^{25,33,35}$, and worldwide ${ }^{24,34,38}$. Having a smoking family member and smoking friend was some of the significant factors found in our study, and this is also consistent with many other studies ${ }^{5,22,24,25,35,39}$.

Though the prevalence of exposure to SHS at home was small, it is noted that the majority were also exposed to SHS outside their homes. The relatively high prevalence of exposure to SHS by these adolescents points to the fact that while Nigeria may have signed the treaty on the implementation of Article 8 of WHO FCTC framework ${ }^{3}$, the enforcement is probably lacking. Unlike some states in Nigeria, there is no state legislation banning public smoking in Oyo State. And, even though the National Tobacco Control Act banning public smoking was enacted in 2015, enforcement of this law has been weak in Oyo State and across the country ${ }^{40}$. Comparing the findings from Nigeria GYTS study ${ }^{26}$ with our research suggests that while SHS exposure inside the home may have decreased, outside exposure has increased in Ibadan over the last decade. Unlike the previous study in $2008^{26}$, this study did not include current smokers. Thus, it would have been expected that the prevalence of exposure to SHS outside home should have been further decreased (since smokers are generally the most exposed to SHS), but this was not the case. The probable explanation for this difference could be that the GYTS survey was carried out among adolescents aged 13-15 years, while all adolescents (10-19 years) were included in the current study.

The high prevalence of exposure to SHS is a public health problem considering the numerous adverse effects that such exposure can cause to adolescents. Thus, urgent steps must be taken to reduce this exposure by ensuring that current smokers are encouraged to quit, and non-smokers are encouraged to make the right decision of avoiding exposure to tobacco smoke. The fact that over one-fifth of the respondents were unaware that exposure to SHS is harmful is a cause of concern, and the level of awareness was higher in the private schools than the public schools. Thus, there is a need for more health education concerning tobacco smoking and its ill-health effects, especially with regard to passive smoking.

What is, however, more surprising is that a higher proportion of the respondents with better perception about the ill-health effects of tobacco smoke were still more exposed to SHS. It thus suggests that having a better perception has not translated to a positive behaviour of avoiding passive smoking among this population. While this may be unusual, it is in agreement with the result of 
the survey conducted among adolescents (13-15 years) in 168 countries $^{34}$. We are inclined to believe that the strong culture norm of respect for elders in this society (Southwest Nigeria) could have impeded their ability to avoid exposure to SHS from smoking parents/elders. This underscores the importance of implementing smoke-free policies, as well as educating smoking parents/elders on the need to stop smoking, and more importantly, the danger to their children and adolescents. As was reported in a similar study conducted among children in Spain ${ }^{41}$, social inequality was found to be independently associated with exposure to SHS, either inside or outside home. Adolescents of low social class were found to be about two times more likely to be exposed to SHS compared with those of high social class. This further underscores the need for health promotion in addressing this problem.

\section{Limitations}

This study is not without its limitations, being of a crosssectional study design causality cannot be inferred. However, since we did not set out to find causality but instead the factors associated with exposure to SHS, we do not consider this to be a problem. Also, the information provided was self-reported, hence, prone to misreporting. While we agree that this is indeed a challenge, we tried to avoid such by explaining to the participants that the questionnaires were anonymized and their responses cannot be traced back to them. With regard to the risk of recall bias, we do not expect this to be a problem because the information sought was exposure in the recent past (last seven days). However, information gathered will highlight the current situation regarding SHS exposure in Ibadan, since the only available report was obtained in 2008. This study is also likely to stimulate similar studies in other cities across the country so that adequate information will be available to formulate an effective public health intervention for the country.

\section{CONCLUSIONS}

The prevalence of exposure to SHS among in-school adolescents in Ibadan, Nigeria, is much higher outside the home than inside the home. Having a smoking family member and smoking friend, going on tobacco-related errands, having the erroneous belief that their peers smoke, and belonging to a low socioeconomic class were the correlates of exposure to SHS. The government must ensure increased compliance with the smoke-free policy. At the same time, tobacco control advocates should intensify efforts in educating adolescents, as well as their smoking relatives and friends about the dangers of active and passive smoking. We encourage further research on the reasons why the perception of harm from exposure to SHS did not translate into avoidance of SHS.

\section{REFERENCES}

1. U.S. Department of Health and Human Services. The Health
Consequences of Smoking- 50 Years of Progress: A Report of the Surgeon General. Atlanta, GA; U.S. Department of Health and Human Services, Centers for Disease Control and Prevention, National Center for Chronic Disease Prevention and Health Promotion, Office on Smoking and Health; 2014. PMID:24455788.

2. International Agency for Research on Cancer. Tobacco Smoke and Involuntary Smoking. In: IARC Monographs on the Evaluation of Carcinogenic Risks to Humans, No. 83. Lyon, France: International Agency for Research on Cancer; 2004. PMID:15285078.

3. World Health Organization. WHO report on the global tobacco epidemic 2017: Monitoring tobacco use and prevention policies. https://www.who.int/tobacco/global_ report/2017/en/. Published July 19, 2017. Accessed June 18, 2020.

4. World Health Organization. WHO report on the global tobacco epidemic 2009: Implementing smokefree environments. https://www.who.int/tobacco/ mpower/2009/gtcr_download/en/. Published 2009. Accessed June 16, 2020.

5. Veeranki SP, Mamudu HM, Zheng S, et al. Secondhand smoke exposure among never-smoking youth in 168 countries. J Adolesc Heal. 2015;56(2):167-173. doi:10.1016/j. jadohealth.2014.09.014

6. Veeranki SP, Mamudu HM, Anderson JL, Zheng S. Worldwide never-smoking youth susceptibility to smoking. J Adolesc Heal. 2014;54(2):144-150. doi:10.1016/j. jadohealth.2013.07.036

7. World Health Organization. Tobacco Free Initiative (TFI): Facts from the WHO Report on the Global Tobacco Epidemic. https://www.who.int/tobacco/global_report/facts/en/ index1.html. Published 2011. Accessed February 28, 2019.

8. Marano C, Schober SE, Brody DJ, Zhang C. Secondhand tobacco smoke exposure among children and adolescents: United States, 2003-2006. Pediatrics. 2009;124(5):12991305. doi:10.1542/peds.2009-0880

9. Bandiera FC, Richardson AK, Lee DJ, He J-P, Merikangas KR. Secondhand Smoke Exposure and Mental Health Among Children and Adolescents. Arch Pediatr Adolesc Med. 2011;165(4):332-338. doi:10.1001/archpediatrics.2011.30

10. Kallio K, Jokinen E, Saarinen M, et al. Arterial Intima-Media Thickness, Endothelial Function, and Apolipoproteins in Adolescents Frequently Exposed to Tobacco Smoke. Circ Cardiovasc Qual Outcomes. 2010;3(2):196-203. doi:10.1161/ CIRCOUTCOMES.109.857771

11.Lehmann N, Dragano N, Peinemann F, et al. Secondhand Smoke Exposure and Coronary Artery Calcification Among Nonsmoking Adults. Epidemiology. 2010;22:S220. doi:10.1097/01.ede.0000392359.68569.db

12. García-Esquinas E, Loeffler LF, Weaver VM, Fadrowski JJ, Navas-Acien A. Kidney function and tobacco smoke exposure in US adolescents. Pediatrics. 2013;131(5):e1415-e1423. doi:10.1542/peds.2012-3201

13. Nadhiroh SR, Djokosujono K, Utari DM. The association 
between secondhand smoke exposure andgrowth outcomes of children: A systematic literature review. Tob Induc Dis. 2020;18(March). doi:10.18332/TID/117958

14. Apostolou A, Garcia-Esquinas E, Fadrowski JJ, McLain P, Weaver VM, Navas-Acien A. Secondhand tobacco smoke: a source of lead exposure in US children and adolescents. Am J Public Health. 2012;102(4):714-722. doi:10.2105/AJPH.2011.300161

15. Ho S-Y, Lai HK, Wang MP, Lam TH. Exposure to Secondhand Smoke and Academic Performance in Non-Smoking Adolescents. J Pediatr. 2010;157(6):1012-1017.e1. doi:10.1016/J.JPEDS.2010.06.013

16. Yan $H$, Ying Y, Xie H, et al. Secondhand smoking increases bladder cancer risk in nonsmoking population: A metaanalysis. Cancer Manag Res. 2018;10:3781-3791. doi:10.2147/CMAR.S175062

17. Moravej-Salehi E, Moravej-Salehi E, Hajifattahi F. Passive smoking: Oral and dental effects. Iran J Public Health. 2015;44(4):600-601. PMID:26056685.

18. Hajifattahi F, Azarshab M, Haghgoo R, Lesan S. Evaluation of the Relationship between Passive Smoking and Oral Pigmentation in Children. J Dent (Tehran). 2010;7(3):119123. PMID:21998785.

19. Avşar A, Darka Ö, Topaloğlu B, Bek Y. Association of passive smoking with caries and related salivary biomarkers in young children. Arch Oral Biol. 2008;53(10):969-974. doi:10.1016/j.archoralbio.2008.05.007

20. Tanaka K, Miyake Y, Sasaki S, et al. Active and passive smoking and tooth loss in Japanese women: Baseline data from the Osaka maternal and child health study. Ann Epidemiol. 2005;15(5):358364. doi:10.1016/j.annepidem.2004.12.005

21.Pi X, Li Z, Jin L, et al. Secondhand smoke during the periconceptional period increases the risk for orofacial clefts in offspring. Paediatr Perinat Epidemiol. 2018;32(5):423427. doi:10.1111/ppe.12497

22. Wang MP, Ho SY, Lam TH. Parental Smoking, Exposure to Secondhand Smoke at Home, and Smoking Initiation Among Young Children. Nicotine Tob Res. 2011;13(9):827-832. doi:10.1093/ntr/ntr083

23. Itanyi IU, Onwasigwe CN, Ossip D, et al. Predictors of current tobacco smoking by adolescents in Nigeria: Interaction between school location and socioeconomic status. Tob Induc Dis. 2020;18(March). doi:10.18332/TID/117959

24.Xi B, Liang Y, Liu Y, et al. Tobacco use and secondhand smoke exposure in young adolescents aged 12-15 years: data from 68 low-income and middle-income countries. Lancet Glob Heal. 2016;4(11):e795-e805. doi:10.1016/S2214-109X(16)30187-5

25. Peltzer K, Peltzer, Karl. Determinants of Exposure to SecondHand Tobacco Smoke (SHS) among Current Non-Smoking In-School Adolescents (aged 11-18 years) in South Africa: Results from the 2008 GYTS Study. Int J Environ Res Public Health. 2011;8(9):3553-3561. doi:10.3390/ijerph8093553 26. Ekanem IOA. Global Youth Tobacco Survey For Nigeria. https://untobaccocontrol.org/impldb/wp-content/uploads/ nigeria_2018_annex-3_GYTS_report_2008.pdf. Published 2008. Accessed June 18, 2020.

27. Lasebikan V, Lasebikan T, Adepoju S. Outdoor smoking in Nigeria: Prevalence, correlates and predictors. BMC Public Health. 2019;19(1):1313. doi:10.1186/s12889-019-7601-8

28. World Health Organization. Tobacco Free Initiative (TFI). Global youth tobacco survey (GYTS). http://www.who.int/ tobacco/surveillance/gyts/en/. Accessed October 5, 2018.

29. Odeyemi KA, Osibogun A, Akinsete AO, Sadiq L. The Prevalence and Predictors of Cigarette Smoking among Secondary School Students in Nigeria. Niger Postgrad Med J. 2009;16(1):40-45. PMID:19305437.

30.Agaku IT, Ayo-Yusuf OA, Vardavas CI, Connolly G. Predictors and patterns of cigarette and smokeless tobacco use among adolescents in 32 countries, 2007-2011. J Adolesc Health. 2014;54(1):47-53. doi:10.1016/j.jadohealth.2013.07.037

31. Mamudu HM, Veeranki SP, John RM, Kioko DM, Ogwell Ouma AE. Secondhand smoke exposure among nonsmoking adolescents in West Africa. Am J Public Health. 2015;105(9):1823-1830. doi:10.2105/AJPH.2015.302661

32. Desalu 00, Onyedum CC, Adewole 00, et al. Secondhand smoke exposure among nonsmoking adults in two Nigerian cities. Ann Afr Med. 2011;10(2):103-111. doi:10.4103/15963519.82069

33. Lee KA, Palipudi KM, English LM, Ramanandraibe N, Asma S. Secondhand smoke exposure and susceptibility to initiating cigarette smoking among never-smoking students in selected African countries: Findings from the Global Youth Tobacco Survey. Prev Med. 2016;91:S2-S8. doi:10.1016/j. ypmed.2016.04.017

34. Veeranki SP, Ogwell Ouma AE, Kioko DM, John RM, Mamudu HM. Secondhand Smoke Exposure Among Nonsmoking Adolescents in West Africa. Am J Public Health. 2015;105(9):1823-1830. doi:10.2105/ajph.2015.302661

35. Owusu D, Mamudu HM, John RM, Ibrahim A, Ouma AEO, Veeranki SP. Never-Smoking Adolescents' Exposure to Secondhand Smoke in Africa. Am J Prev Med. 2016;51(6):983-998. doi:10.1016/j.amepre.2016.08.040

36. Oyedeji GA. Socioeconomic and Cultural Background of Hospitalized Children in Ilesha. Niger J Paediatr. 1985;12(4):111-117. http://www.njpaediatrics.com/1985/ v12n4/2Socio\%20 economic\%20and\%20Cultural\%20 Background $\% 20$ of $\% 20$ Hospitalized $\% 20$ Children $\% 20 \mathrm{in} \% 20$ Ilesha.pdf. Accessed June 18, 2020.

37. Fagbule OF, Kanmodi KK, Aladelusi TO. Secondhand tobacco smoke exposure and attitudes towards tobacco ban: A pilot survey of secondary school students in Ibokun Town, Nigeria. International Journal of Child and Adolescent Health. 2018;11(3). https://www.questia.com/library/ journal/1P4-2188903377/secondhand-tobacco-smokeexposure-and-attitudes-towards. Accessed August 3, 2018.

38. Öberg M, Jaakkola MS, Woodward A, Peruga A, Prüss-Ustün A. Worldwide burden of disease from exposure to secondhand 
smoke: a retrospective analysis of data from 192 countries. Lancet. 2011;377(9760):139-146. doi:10.1016/S01406736(10)61388-8

39. Gilman SE, Rende R, Boergers J, et al. Parental smoking and adolescent smoking initiation: an intergenerational perspective on tobacco control. Pediatrics. 2009;123(2):e274-81. doi:10.1542/peds.2008-2251

40.Ukwueze F, Ogbuabor C, Okiche E. Tobacco Control Legislation and Policy in Nigeria: Much Barking without Biting. Elixir Inter Law. https://www.researchgate.net/ publication/322790176_Tobacco_Control_Legislation_and_ Policy_in_Nigeria_Much_Barking_without_Biting. Published 2018. Accessed June 16, 2020.

41.López MJ, Arechavala T, Continente X, Schiaffino A, PérezRíos M, Fernández E. Social inequalities in secondhand smoke exposure in children in Spain. Tob Induc Dis. 2018;16(April):1-6. doi:10.18332/tid/85717

\section{ACKNOWLEDGEMENTS}

We acknowledge the contributions of C.A. Ojeh, S.T. Akinrodoye, Y.D. Olatunji, O.I. Oni, C.S. Eneh, T.I. Gbademu, Q.A. Adeyemo, B.O. Animashaun and O.S. Jideofor.

\section{CONFLICTS OF INTEREST}

The authors have completed and submitted the ICMJE Form for Disclosure of Potential Conflicts of Interest and none was reported.

FUNDING

There was no source of funding for this research.

\section{AUTHORS' CONTRIBUTIONS}

OFF conceived the idea for the study, contributed to its design and in the analysis and interpretation of the data, and in drafting the manuscript. MEO contributed to the conception of the study and its design, and the acquisition of data. Both authors reviewed, edited and approved the final manuscript.

\section{PROVENANCE AND PEER REVIEW}

Not commissioned; externally peer reviewed. 